\title{
Recycling Graphite for Vanadium Redox Flow Batteries: Options for Usage and Critical Integredients
}

ISSN: 2576-8840

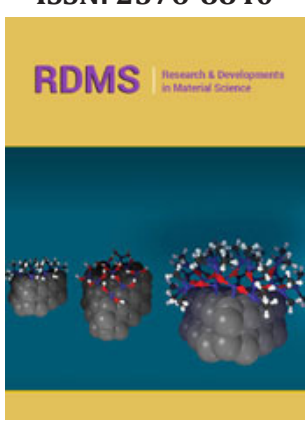

*Corresponding author: Hickmann $\mathrm{T}$, Eisenhuth GmbH \& Co. KG, FriedrichEbert-Straße 2013, 37520 Osterode, Germany

Submission: 海 April 27, 2020

Published: 眥 May 08, 2020

Volume 13 - Issue 2

How to cite this article: Hickmann $\mathrm{T}$. Recycling Graphite for Vanadium Redox Flow Batteries: Options for Usage and Critical Integredients. Res Dev Material Sci. 13(2). RDMS.000807. 2020.

DOI: 10.31031/RDMS.2020.13.000807

Copyright@ Hickmann T, This article is distributed under the terms of the Creative Commons Attribution 4.0 International License, which permits unrestricted use and redistribution provided that the original author and source are credited.

\section{Hickmann T*}

Eisenhuth GmbH \& Co. KG, Germany

\begin{abstract}
Modern energy systems, such as redox flow batteries (RFB), recently are becoming increasingly popular in the special isttrade [1-5]. Despite a numberof demonstrative tests on redox flow batteries [47], upto now there does only orginal Carbon material exist. However, it is necessary to look at Recycling mateirals. There are a certain number how to get recycled graphite. However, when deciding to use these materials, it is necessary to have a close look of the characteristics of these materials.
\end{abstract}

Keywords: Recycling; Vanadium redox flow batteries; Graphite; Compound; Bipolar plates; Carbon; Recycling

Abbreviations: C: Carbon; FE: Iron; N: Nitrogen, SEM: Scanning Electrone Microscope; VRB: Vanadium Redox Flow Batteries

\section{Introduction}

Already in 2010, a working group of the European Commission, analysed arround 41 materials and came to the conclusion about their criticality and the risk of supply safety and their ecomic importance. As a result, around 14 matrials were judged critically, and this included graphite as well [8]. For some industry areas, Graphite is estimated as a critical material [9]. For this reason, the importance of Recycling Graphite is growing and it is necessary to look for recycling material.

\section{Discussion}

As for the option how to get the recycled graphite-material, there are different possibilities. These possibilities aresummarized in Table 1.

Table 1 shows different option show Recycling Carbon can be used. The table shows that there are 2 materials which have a good availability. Industrial Recycling Carbin and Recyclung out of Production. Since these condpathis evident how the material are composed together, it make sense to look at the material whis is from Industrial Recycling Graphite. For this reason, A Scanning Electoning Microscope (SEM) isused. With the SEM it is not possible to have a quantitative Anaylsys.

Table 1: Options of recycling carbon.

\begin{tabular}{|c|c|c|c|}
\hline Material & Availability & $\begin{array}{c}\text { High / Low Efforts of } \\
\text { Pre-Processing }\end{array}$ & $\begin{array}{c}\text { Price Estimation for } \\
\text { Higher Volume }\end{array}$ \\
\hline Industrial Recycling Carbon & ++ & Low Efforts & ++ \\
\hline Recycling out ofProduction & ++ & Medium Efforts & +++ \\
\hline Recycling fromused System & -- & High Efforts & ++ \\
\hline MethaneCracking & 0 & Medium Efforts & $?$ \\
\hline Pyrolized Carbon & - & Very high efforts & -- \\
\hline
\end{tabular}

Figure 1 shows a SEM of a Carbon Composite material with $72 \%$ Fillerof Industrial Recycling Carbon. 

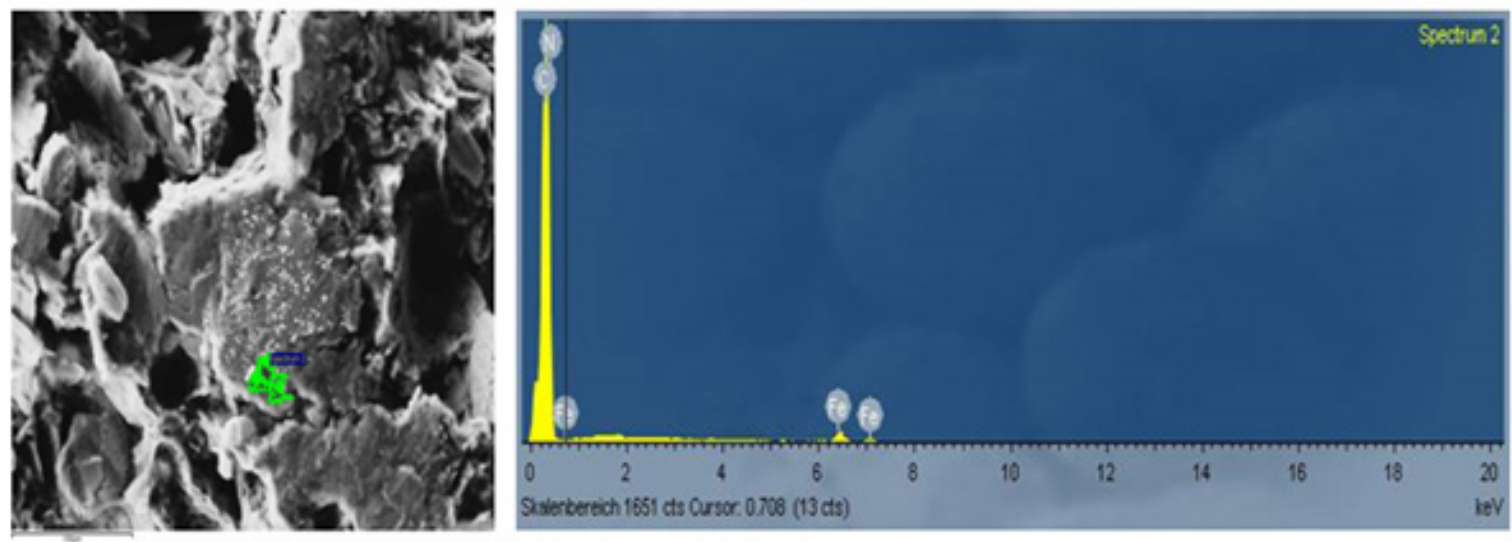

Figure 1: SEM of a carbon composite material filled with $72 \%$ graphite.

Looking at the SEM of Figure 1, the specrte of points is shown. The area with the green color: Here the iron-concentration is fairly high. In fact, Iron is contaminating the Redox Flow Battery, for this reason, it has to be avoided [7].

Generally spoken, at a SEM the area of analysis is fairly small. During the test, Eisenhuth has taken 10 different test areas. However, it is possible the at there are still some other materials in the Compound. During, the measurement, there were found some iron and ironoxide particles. In addtion, the following materials could be found:
a) Calcium
b) Aluminium
c) Zirconium
d) Vanadium
e) Titanium
f) Sulfor

As far as the contamination in a VRB is concerned, the Aluminium and Titanium have a negative impact on the performance. The other materials how ever are neutral.

\section{Conclusion}

The recycling components produced can be manufactured easily and cost-effective and can be integrated without any problems into a redox flow test system. For the SEM as a testing system, the corresponding characteristics can be measured immediately. But only on a small spot. The SEM shows, however, that is very well suited for testing critical and non critical materials. Critical Materials in a VRB are Iron, Aluminium and Titatnium, where as
Calcium, Zirconium, Vanadium and Sulfor are uncritical [7]. As a next step it is worth to consider other materials such as the frame or the Membrane in order to decide to use recyclable material.

\section{Acknowledgement}

The authorthanksthe Federal Ministryof Economy and Energyforthedonation in theproject Re3dox fortheusageof Recycling materials in Redox Flow Batteries.

\section{References}

1. Skyllas-Kazacos M, Chakrabarti MH, Hajimolana SA, Mjalli FS, Saleem M (2011) Progress in flow batters research and development. Journal of the Electrochemical Society 158 (8): R55-R79.

2. Weber AZ, Mench MM, Meyers JP, Ross PN, Gostick JT, et al. (2011) Redox flow batteries: a review. Journal of Applied Electrochemistry 41: 11371164.

3. Noack J, Roznyatovskaya N, Herr T, Fischer P (2015) The chemistry of redox-flow batteries angew. Chem Int Ed 54: 9776-9809.

4. Quarthal D, Novotyn J, Oetken M (2017) Color play in redox flow batteries. News from Chemistry 65: 672-675

5. Rosenberg D, Pansegrau S, Wachholz M, Rehling A, Busker M, et al. (2017) Redox flow batteries - organic batteries with future prospects. CHEMKON 24: 25-340.

6. Media package from the Siemens Foundation on the topic "Capacitor, hydrogen, redox flow - we store regenerative energy".

7. Hempelmann R (2015) Redox-flow-batterie. In: Mischnick P, DeusingGottschalk I (Eds.), Chemistry and energy - what is there? What to do ?, Druck- und Verlagshaus Zarbock GmbH \& Co.KG Frankfurt, Germany, pp. 38-39.

8. http://ec.europa.eu/enterprise/policies/raw-materials/files/docs/ report-b_en.pdf

9. Deutsche Rohstoffagentur DERA (2012) DERA-Rohstoffliste 2012, Berlin, Germany. 